\title{
Mechanical properties and fire retardancy of bidirectional reinforced composite based on biodegradable starch resin and basalt fibres
}

\author{
T. Wittek*, T. Tanimoto \\ Shonan Institute of Technology, Tsujido-Nishikaigan 1-1-25, Fujisawa, Kanagawa 251-8511, Japan \\ Received 1 August 2008; accepted in revised form 3 October 2008
}

\begin{abstract}
Environmental problems caused by extensive use of polymeric materials arise mainly due to lack of landfill space and depletion of finite natural resources of fossil raw materials, such as petroleum or natural gas. The substitution of synthetic petroleum-based resins with natural biodegradable resins appears to be one appropriate measure to remedy the above-mentioned situation. This study presents the development of a composite that uses environmentally degradable starch-based resin as matrix and basalt fibre plain fabric as reinforcement. Prepreg sheets were manufactured by means of a modified doctor blade system and a hot power press. The sheets were used to manufacture bidirectional-reinforced specimens with fibre volume contents ranging from 33 to $61 \%$. Specimens were tested for tensile and flexural strength, and exhibited values of up to 373 and $122 \mathrm{MPa}$, respectively. Through application of silane coupling agents to the reinforcement fibres, the flexural composite properties were subsequently improved by as much as $38 \%$. Finally, in order to enhance the fire retardancy and hence the applicability of the composite, fire retardants were applied to the resin, and their effectiveness was tested by means of flame rating (according to UL 94) and thermogravimetric analysis (TGA), respectively.
\end{abstract}

Keywords: biodegradable polymers, starch resin, basalt fibres, silane coupling agents, fire retardants

\section{Introduction}

The primary field of application for fibre reinforced polymer composites is the aerospace industry. For several years, however, composite materials have been increasingly used for various other technical tasks, where it is beneficial to apply lightweight construction materials which have high strength and stiffness characteristics. The favourable specific properties of fibre reinforced polymer composites are based on the low density of the matrix resins used, and the high strength of the embedded fibres.

Regarding utilisation after service life, conventional fibre reinforced composites are problematic. The combination of miscellaneous, often highly durable components complicates the recycling process considerably, and landfill disposal or incineration are becoming increasingly difficult due to environmental concerns and legal requirements. An additional problem resulting from the use of polymer resins as matrix material, is the depletion of finite natural petrochemical resources increasingly accompanied by a rise in costs.

A possible solution to these issues may result from the use of natural fibre reinforced polymers based on renewable resources, or 'green' composites. By embedding natural fibres into matrices based on biopolymers, fibre reinforced polymers are obtained which integrate more readily into the natural biodegradation cycles, for example by $\mathrm{CO}_{2}$-neutral incineration, which includes recovery of energy, or by composting. Advantages of biodegradable com-

*Corresponding author, e-mail: wittek@mate.shonan-it.ac.jp

(c) BME-PT and GTE 
posites include: biological degradation, reduction in the volume of waste, preservation of fossil-based raw materials, and protection of climate through reduction of carbon dioxide emission.

Although research into 'green' composites has been conducted worldwide since at least the mid1990s, practical application of these composites is still in the early stages. Most fibres that are currently used for manufacturing of 'green' composites are cellulose-based plant fibres. Although cellulose-based fibres possess several advantages, including low cost, low density, high specific mechanical properties and biodegradability, they exhibit some severe drawbacks. These include moisture absorption leading to fibre swelling, low thermal resistance, anisotropic fibre properties, low compressive and transverse strength, local or seasonal variations in quality and poor compatibility between the hydrophilic fibres and hydrophobic polymer matrices $[1,2]$.

The main aims of our research are twofold: to contribute to the enhancement of the application possibilities of 'green' composites by exploring natural mineral basalt fibres as reinforcement in biodegradable polymeric resins, and to develop a composite material that has mechanical properties similar to those of conventional glass fibre reinforced polymeric composites based on petrochemical resources, while exhibiting a lower degree of environmental impact.

Due to processability considerations and in order to achieve high fibre content, it was decided to use a resin emulsion based on thermoplastic starch and polycaprolactone (PCL) in combination with the basalt fibres. PCL is applied because it provides good mechanical properties, such as favourable tensile strength and elongation, and shows good compatibility with many types of polymers. On the other hand, starch helps to lower the cost of the final product and to improve several physical properties. In order to obtain thermoplastic properties, but also to overcome the poor miscibility between starch and PCL, denaturation of starch is one possible method. Other methods to overcome this miscibility issue, which have been reported recently, include acylation of starch in anhydride solutions [3], grafting of PCL by acrylic acid [4], addition of a compatibiliser constituted by modified PCL or the addition of a silane coupling agent [5].
The only ingredient used in the manufacture of basalt fibres is solidified volcanic lava in which $\mathrm{SiO}_{2}$ accounts for the main part, followed by $\mathrm{Al}_{2} \mathrm{O}_{3}$, then $\mathrm{Fe}_{2} \mathrm{O}_{3}, \mathrm{FeO}, \mathrm{CaO}$ and $\mathrm{MgO}$ [6-8]. Basalt rocks are classified according to the $\mathrm{SiO}_{2}$ content as alkaline (up to $42 \% \mathrm{SiO}_{2}$ ), mildly acidic (43 to $46 \%$ $\mathrm{SiO}_{2}$ ) and acidic basalts (over $46 \% \mathrm{SiO}_{2}$ ). Only acidic type basalts satisfy the conditions for fibre preparation [9]. Basalt fibres are extruded from basalt rock through a melting process without the application of additives. The fibres are cost-effective and possess several excellent properties, such as outstanding sound and thermal insulation, nonflammability and good mechanical strength $[7,10$, 11]. The mechanical properties of basalt fibre are similar or superior to those of plant fibre and glass fibre. Also, basalt fibre is environmentally and ecologically harmless, and free of carcinogens and other health hazards [12].

Noteworthy recent research on basalt fibre composites includes the development of a new method for the production of short basalt fibres and related extensive results on the properties of basalt fibre reinforced hybrid thermoplastic and thermoset composites [11, 13-16].

Recent reports on polymer resin matrices reinforced with continuous basalt fibres include unidirectional basalt fibres and cross-ply in epoxy and phenolic resin [17], basalt twill weave reinforced epoxy and vinyl resin for applications in transportation [18, 19], and unidirectional basalt yarn as reinforcement in wheat gluten [20].

The initial steps of our research, as previously reported in [21], were to select an appropriate manufacturing method and to identify the processing parameters by manufacturing unidirectional basalt fibre reinforced 'green' composites and testing their mechanical properties, such as tensile strength, flexural strength and interlaminar shear strength. In this paper, we are focusing on the manufacturing and characterization of bidirectional basalt fibre reinforced composites, with the intent of increasing the applicability of these materials and turning them into functioning engineering composites. We also analysed the effectiveness of several additives with the aim of improving the composites mechanical properties and fire retardancy. The research on flame retardancy of biodegradable composites in particular is a subject which was hardly studied 
until recently. The work of Matkó et al., where the use of ammonium polyphosphate in different biocomposites was reported [22], is worth mentioning as the pioneering study in this field.

\section{Experimental}

\subsection{Materials}

\subsubsection{Polymer matrix}

The resin used during this study, termed Landy CP300 and provided by Miyoshi Yushi Inc., is an emulsion with approximately $40 \%$ solid content, where particles with an average diameter of $4.2 \mu \mathrm{m}$ are dispersed in water. CP-300 is a blend of Cornpol and polycaprolactone. Cornpol is a starch based biodegradable plastic, produced by Nihon Starch Ltd., Japan, by denaturating cornstarch with natural fats into an aliphatic ester [23]. The properties of CP-300 are summarized in Table 1.

\subsubsection{Reinforcement fibres}

We have chosen basalt plain weave fabric (BT-8) purchased from Sudaglass Fiber Technology Inc., Russia, as the reinforcement material for our research. BT-8 has an area density of $210 \mathrm{~g} / \mathrm{m}^{2}$, a thickness of $0.18 \mathrm{~mm}$, and warp and weft densities of 10 and 8 yarns $/ \mathrm{cm}$, respectively. The properties of the single fibres are shown in Table 1.

Table 1. Properties of base materials

\begin{tabular}{|l|c|c|}
\hline & CP-300 resin & Basalt fibres \\
\hline Density $\left[\mathrm{g} / \mathrm{cm}^{3}\right]$ & 1.17 & 2.7 \\
\hline Diameter $[\mu \mathrm{m}]$ & - & 13.1 \\
\hline Tensile strength $[\mathrm{MPa}]$ & 8.3 & 1540 \\
\hline Elastic modulus $[\mathrm{GPa}]$ & 0.3 & 86 \\
\hline Elongation at break $[\%]$ & 16.8 & 2.6 \\
\hline Flexural strength $[\mathrm{MPa}]$ & 10.2 & - \\
\hline Flexural modulus $[\mathrm{GPa}]$ & 0.5 & - \\
\hline
\end{tabular}

Burn-off tests indicated that the basalt woven cloth used in this study was furnished with about $1.4 \mathrm{wt} \%$ of proprietary sizing applied by the manufacturer. Although no information could be obtained about the nature of this sizing, initial tests were carried out with the fibre material in the state it was received.

\subsubsection{Coupling agents}

As initial tests suggested that the proprietary sizing applied by the manufacturer was not compatible with thermoplastic resins, two types of silane surface treating agents were selected for further use in this study. The coupling agents used were 3-aminopropyl triethoxysilane (APTS), produced by ShinEtsu Chemical Co., Ltd., Japan, and 3-(triethoxysilyl)propyl isocyanate (TSPI), produced by Tokyo Chemical Industry Co., Ltd, Japan. The chemical structures and descriptions of these agents are listed in Table 2.

Both silane coupling agents were selected due to their known compatibility with thermoplastic resins and solubility in water. APTS is a well-studied monomeric silane which has been successfully applied with basalt fibres in several resin systems [24-26] and has shown its compatibility to different thermoplastic matrices, such as polycarbonate/ silicon carbide [27] and PCL/starch/pine leaf [5].

\subsubsection{Fire retardants}

In order to preserve the environmentally friendly character of the 'green' composites when using fire retardants, it was decided to use a phosphorusbased system (Novared 120, provided by Rinkagaku Kogyo Ltd., Japan) and a metallic hydroxide system based on magnesium hydroxide (Magnifin H-7, provided by Albemarle Corporation, USA),

Table 2. Chemical structures and descriptions of silane coupling agents

\begin{tabular}{|c|c|c|c|c|}
\hline Chemical structure and name & Manufacturer & Product number & Designation & Molecular weight \\
\hline $\begin{array}{c}\mathrm{OCH}_{2} \mathrm{CH}_{3} \\
\text { I } \\
\mathrm{H}_{2} \mathrm{~N}-\left(\mathrm{CH}_{2}\right)_{3}-\mathrm{Si}-\mathrm{OCH}_{2} \mathrm{CH}_{3} \\
\text { I } \\
\mathrm{OCH}_{2} \mathrm{CH}_{3} \\
\text { 3-aminopropyl triethoxysilane }\end{array}$ & Shin-Etsu Chemical Co., Ltd. & LS-3150 & APTS & 221.4 \\
\hline $\begin{array}{c}\mathrm{OCH}_{2} \mathrm{CH}_{3} \\
\text { I } \\
\mathrm{O}=\mathrm{C}=\mathrm{N}-\left(\mathrm{CH}_{2}\right)_{3}-\mathrm{Si}-\mathrm{OCH}_{2} \mathrm{CH}_{3} \\
\text { I } \\
\mathrm{OCH}_{2} \mathrm{CH}_{3} \\
\text { 3-(triethoxysilyl)propyl isocyanate }\end{array}$ & Tokyo Chemical Industry Co., Ltd. & I0556 & TSPI & 247.4 \\
\hline
\end{tabular}


Table 3. Chemical structures and descriptions of fire retardants

\begin{tabular}{|l|l|l|c|c|l|}
\hline \multicolumn{1}{|c|}{$\begin{array}{c}\text { Chemical structure } \\
\text { and name }\end{array}$} & \multicolumn{1}{|c|}{ Manufacturer } & \multicolumn{1}{c|}{$\begin{array}{c}\text { Product } \\
\text { name }\end{array}$} & Designation & $\begin{array}{c}\text { Specific } \\
\text { weight }\end{array}$ & \multicolumn{1}{c|}{ Consistency } \\
\hline $\begin{array}{l}\mathrm{P}_{\mathrm{n}} \\
\text { Red phosphor }\end{array}$ & Rinkagaku Kogyo Co.,Ltd. & Novared 120 & RP & 2.34 & $\begin{array}{l}\text { Phosphor: } 86 \% \\
\text { Coating: } 14 \%\end{array}$ \\
\hline $\begin{array}{l}\mathrm{Mg}(\mathrm{OH})_{2} \\
\text { Magnesium hydroxide }\end{array}$ & Albemarle Corporation & Magnifin H-7 & $\mathrm{MH}$ & 2.40 & $\mathrm{Mg}(\mathrm{OH})_{2}: 99.8 \%$ \\
\hline
\end{tabular}

instead of widely used, but rather toxic fire retardant additives such as halogens. Novared 120 is a red powder with a sublimation temperature of $416^{\circ} \mathrm{C}$, while Magnifin $\mathrm{H}-7$ is a white powder with a median particle size of $0.8-1.1 \mu \mathrm{m}$. Other properties and descriptions are displayed in Table 3.

\subsection{Methods}

\subsubsection{Sample preparation}

Samples were manufactured using the doctor blade-assisted prepreg sheet method, developed in accordance to [28]. Initially, pre-form sheets were manufactured by impregnating as-received basalt fibre plain weave using the doctor blade system (DP-150, Tsugawa Seiki Seisakusho Ltd., Japan), then drying the sheets overnight and cutting them to size. The pre-form sheets were then subjected to an initial pressure and heat application process using a hot power press (WF-37, Shinto Co., Japan), which converted them into prepreg sheets (prepreg moulding). After putting the sheets onto the lower plunger of the hot press, the heating device was engaged and the sheets heated until they reached a processing temperature of $150^{\circ} \mathrm{C}$. Marginal pressure was then applied for 30 minutes to enable trapped air to escape and facilitate the impregnation of the matrix between the fibres. The pressure was subsequently increased to $4.9 \mathrm{MPa}$, while the heating device was switched off, allowing the sample to cool to room temperature at a rate of

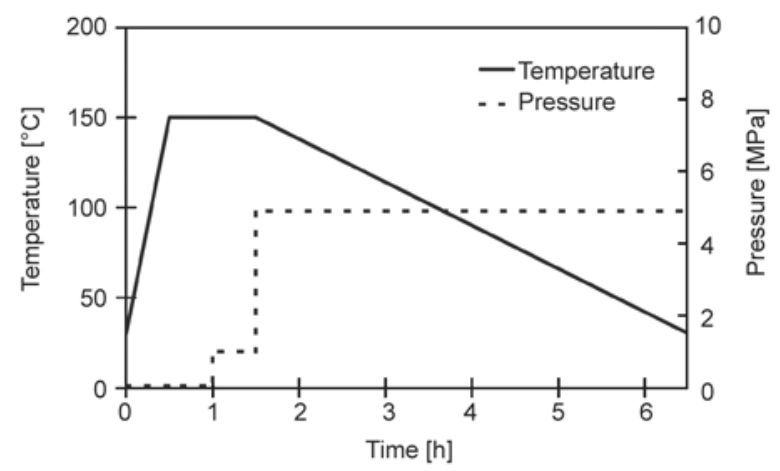

Figure 1. Process chart for prepreg and sample moulding

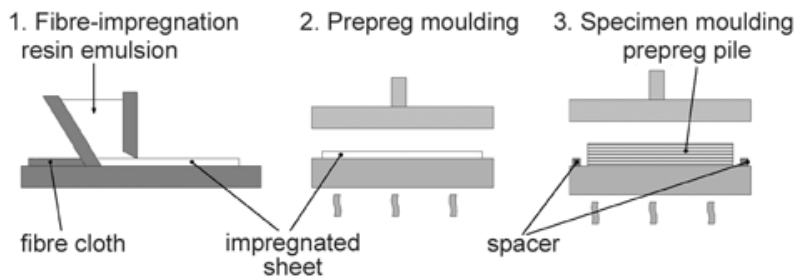

Figure 2. Composite manufacturing process

approximately $0.5^{\circ} \mathrm{C} / \mathrm{min}$, as detailed in the process chart (Figure 1). Afterwards, several layers of prepreg sheets were stacked and subjected again to a pressure and heat application process (sample moulding), applying the same equipment and parameters as in the previous manufacturing stage. Spacers were used during sample moulding to achieve a predefined sample thickness. The manufacturing process is depicted in Figure 2.

In order to determine the influence of the volume fibre fraction on the mechanical properties, textile composite samples were produced with varying numbers of prepreg-sheets. The number of prepregsheet layers used to manufacture tensile test specimens ranged from 4 to 7 , while 6 to 12 layers of prepreg-sheets were used to manufacture flexural test specimens. The number of layers corresponded to fibre volume ranges of 32 to $61 \mathrm{vol} \%$ and 24 to $51 \mathrm{vol} \%$, respectively.

\subsubsection{Application of coupling agents}

Before application of the silane coupling agent, the proprietary sizing with which the basalt fibres were coated by the manufacturer was burned off in a furnace at $350^{\circ} \mathrm{C}$ for 30 minutes. The coupling agents were then applied by first dissolving them in distilled water to form an aqueous solution. An important prerequisite in the preparation of the aqueous silane solution, and thus in the selection of the coupling agents, was the desire to keep the solution as plain as possible without the addition of chemical products other than the silanes. This was done with the intention of keeping the preparation process 
itself as simple as possible and to avoid further components with potential negative environmental impact. Hence two water-soluble silane coupling agents, as described in 2.1.3, were chosen for application.

Although there are other parameters, such as treatment time, temperature and solvent composition, one of the principal experimental parameters for the optimised silane treatment on the fibre surface is concentration of the aqueous solution. As was previously shown in [29], the effectiveness of the silane treatment is more dependent on the silane concentration than on the dipping time. Therefore, aqueous solutions with 1,2 and $3 \mathrm{wt} \%$ were prepared to evaluate the optimum concentration, while the dipping time was kept constant at 2 hours.

After applying the aqueous silane solution to the fibres, the fibres were removed and allowed to air dry for approximately 20 hours. A small sample of the dry, treated basalt fibre cloth was weighed and placed in a furnace at $350^{\circ} \mathrm{C}$ for 2 hours to remove any chemicals from the surface. After removal from the furnace, the samples were again weighed to determine the amount of silane coupling agent that had been burned off in the furnace. The results of this burn off indicated that the silane treated basalt fibre cloth had about $0.5 \mathrm{wt} \%$ silane coupling agent on the surface, which complies with the practical experience that only a very small proportion of silane at the interface is sufficient to provide marked improvement in composite properties [30]. Subsequently, the basalt fibres in combination with $\mathrm{CP}-300$ resin were subject to the manufacturing procedure described in chapter 2.2.1.

To evaluate the effect of the silane coupling agent, laminate samples with 8 layers of basalt woven cloth, a fibre volume content of approximately $34 \mathrm{vol} \%$, untreated and treated in APTS and TSPI solutions with different concentrations were tested for flexural strength.

\subsubsection{Application of fire retardants}

Composite samples with fire retardants were tested for flammability using horizontal and vertical burning tests, as well as being tested for flexural strength. Samples were prepared utilizing the doctor blade assisted prepreg sheet method as described in 2.2.1. The basalt fibres were burned at $350^{\circ} \mathrm{C}$ for 30 minutes to remove the sizing applied by the manufacturer and treated in 1\%-APTS solution. The fire retardant additives were mixed by hand directly into the liquid resin before impregnation of the fibre. The uniform distribution of the retardants in the resin was visible by the uniform change of the resin colour.

When handling red phosphorus it is important to notice that by prolonged contact with water, or contact with water under elevated temperature, slow decomposition occurs. This decomposition can cause traces of hydrogen phosphide, a toxic and flammable gas, to be formed in time. As shown by the results of the retardancy test, described in 3.3, the contact with the water content of the liquid resin was not prolonged enough to decrease the functionality of the red phosphorus noticeably.

Laminate flexural samples with a thickness of $2 \mathrm{~mm}$ and 8 layers of basalt woven cloth, and combustion performance samples with a thickness of $1 \mathrm{~mm}$ and 4 layers of woven cloth, corresponding to a volume fibre fraction of approximately $34 \%$ and a weight fraction of approximately $55 \%$ were manufactured. Fire retarded composite samples were prepared with fire retardant additive amounts of 9 and $4.5 \mathrm{wt} \%$.

\subsection{Tests}

\subsubsection{Tensile strength}

An Instron universal material-testing machine, model 4200, was used for the tension tests. The tests were carried out according to [31] with a displacement rate of $1.0 \mathrm{~mm} / \mathrm{min}$. All samples had a length of $200 \mathrm{~mm}$, a width of $10 \mathrm{~mm}$ and a thickness of $1 \mathrm{~mm}$. End tabs with chamfered edges and manufactured of cross-plied glass fibre reinforced epoxy resin were attached to the specimens using an appropriate adhesive to avoid untimely failure at the load transmission points. During the tests the initiated load was recorded by an attached computer system, while the tensile strain was quantified by means of strain gauges.

\subsubsection{Flexural strength}

A Shimadzu AGS-1000B universal material-testing machine was used for the flexural tests. The tests were carried out according to [32] as 3-point-bending tests, with a displacement rate of $1.0 \mathrm{~mm} / \mathrm{min}$. Samples had a length of $60 \mathrm{~mm}$, a width of $15 \mathrm{~mm}$ 
and a thickness of $2 \mathrm{~mm}$. During the tests the initiated load was recorded by an attached computer system; the flexural strain was quantified by means of strain gauges.

\subsubsection{Combustion performance}

Flammability was characterised by UL 94 tests, according to [33]. The UL 94 method classifies the materials with horizontal and vertical burning tests. In the horizontal burning test, specimens with a length of $127 \mathrm{~mm}$, width of $12.7 \mathrm{~mm}$ and thickness of $1 \mathrm{~mm}$ are held horizontally and tilted at a $45^{\circ}$ angle. A flame fuelled by natural gas is applied to the freestanding end of the specimens for $30 \mathrm{sec}-$ onds. The time for the flame to reach from the first reference mark at $25.4 \mathrm{~mm}$ from the ignited end to the second reference mark at $101.6 \mathrm{~mm}$ is measured. Three specimens are tested for each sample. When the burning rate is lower than $76.2 \mathrm{~mm} / \mathrm{min}$ or the specimens stop burning before the second mark, they are rated with the lowest fire retardancy rating, HB. The most flammable polymers, which cannot be classified according to this method, are marked with a code NR (no rating).

For vertical testing, a specimen with the same dimensions as those used in the horizontal case, is supported in a vertical position and the flame applied to the bottom of the specimen. The flame is applied for ten seconds and then removed until flaming stops at which time the flame is reapplied for another ten seconds and then removed. Two sets of five specimens, which were prepared under different conditions, are tested per sample. One set of specimens was kept under room temperature for 2 days; the other set was kept for 7 days in a hot air kiln at $60^{\circ} \mathrm{C}$ and afterwards for 4 hours in a desiccator. If the specimens do not burn with flaming or glowing combustion up to the specimen holding clamp, they receive a vertical flame rating. V0 represents an exceptionally flame retardant material, while V2 and V1 indicate flame retardancy levels between $\mathrm{V} 0$ and $\mathrm{HB}$.

\subsubsection{Thermal analysis}

Thermogravimetric analysis (TGA) measurements were performed with a TG1180 thermal analyzer, produced by Rigaku Corporation, Japan, using $20 \mathrm{mg}$ samples at a heating rate of $10^{\circ} \mathrm{C} / \mathrm{min}$ up to $500^{\circ} \mathrm{C}$ in air.

\subsubsection{Morphology observation}

The surfaces of the specimens obtained after the UL94 burning tests, as well as the tensile and flexural samples, were observed with a DSC-T70 digital camera, produced by Sony Corp., Japan.

\section{Results and discussion}

\subsection{Mechanical properties as a function of fibre volume fraction}

Using as-received basalt fibre plain weave in combination with CP-300, 'green' composites with a tensile strength of more than $370 \mathrm{MPa}$ and a flexural strength of about $120 \mathrm{MPa}$ have been manufac-

Table 4. Effect of fibre volume content on tensile properties; CP: CP-300 resin; BaF: basalt fibres; AR: as received

\begin{tabular}{|l|c|c|c|c|}
\hline \multicolumn{1}{|c|}{ Sample designation } & $\begin{array}{c}\text { Fibre volume fraction } \\
{[\%]}\end{array}$ & $\begin{array}{c}\text { Tensile strength } \\
{[\mathbf{M P a}]}\end{array}$ & $\begin{array}{c}\text { Elastic modulus } \\
{[\mathbf{G P a}]}\end{array}$ & $\begin{array}{c}\text { Fracture strain } \\
{[\%]}\end{array}$ \\
\hline $\mathrm{CP}$ & 0 & $8.3 \pm 0.7$ & $0.3 \pm 0.1$ & $16.75 \pm 5.75$ \\
\hline $\mathrm{CP} / \mathrm{BaF}(\mathrm{AR}) 32$ & 32 & $280.9 \pm 15.2$ & $11.8 \pm 0.2$ & $3.30 \pm 0.12$ \\
\hline $\mathrm{CP} / \mathrm{BaF}(\mathrm{AR}) 37$ & 37 & $301.4 \pm 43.8$ & $13.4 \pm 1.7$ & $3.01 \pm 0.11$ \\
\hline $\mathrm{CP} / \mathrm{BaF}(\mathrm{AR}) 50$ & 50 & $365.8 \pm 31.8$ & $17.3 \pm 0.5$ & $3.13 \pm 0.25$ \\
\hline $\mathrm{CP} / \mathrm{BaF}(\mathrm{AR}) 61$ & 61 & $373.3 \pm 14.7$ & $15.8 \pm 0.4$ & $3.74 \pm 0.12$ \\
\hline
\end{tabular}

Table 5. Effect of fibre volume content on flexural properties; CP: CP-300 resin, BaF: basalt fibres, AR: as received

\begin{tabular}{|l|c|c|c|}
\hline \multicolumn{1}{|c|}{ Sample designation } & Fibre volume fraction [\%] & Flexural strength [MPa] & Flexural modulus [GPa] \\
\hline $\mathrm{CP}$ & 0 & $10.2 \pm 0.3$ & $0.5 \pm 0.1$ \\
\hline $\mathrm{CP} / \mathrm{BaF}(\mathrm{AR}) 24$ & 24 & $72.8 \pm 3.0$ & $9.7 \pm 0.8$ \\
\hline $\mathrm{CP} / \mathrm{BaF}(\mathrm{AR}) 34$ & 34 & $99.0 \pm 10.0$ & $15.2 \pm 2.5$ \\
\hline $\mathrm{CP} / \mathrm{BaF}(\mathrm{AR}) 37$ & 37 & $100.6 \pm 13.9$ & $15.2 \pm 3.4$ \\
\hline $\mathrm{CP} / \mathrm{BaF}(\mathrm{AR}) 42$ & 42 & $114.2 \pm 5.5$ & $17.4 \pm 0.3$ \\
\hline $\mathrm{CP} / \mathrm{BaF}(\mathrm{AR}) 51$ & 51 & $122.3 \pm 13.4$ & $19.7 \pm 0.9$ \\
\hline
\end{tabular}



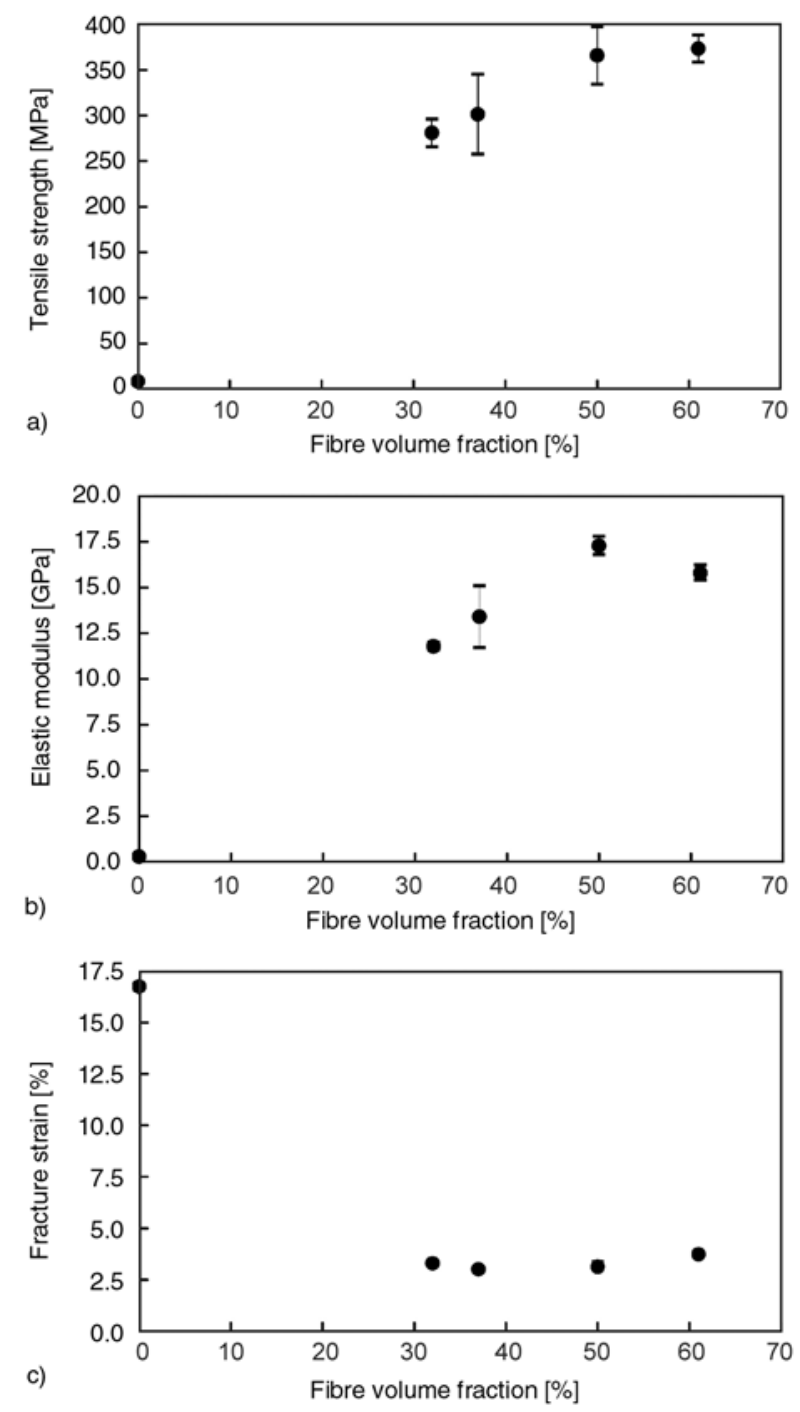

Figure 3. Effect of fibre volume fraction on tensile strength (a), elastic modulus (b) and fracture strain (c)

tured. The composites' tensile and flexural property values are shown in Tables 4 and 5, respectively.

Figure 3 presents the tensile strength and the elastic modulus of the plain weave reinforced composite against the fibre volume content. The tensile strength of the composite achieves a value of $281 \mathrm{MPa}$ with a volume fibre content of $32 \%$. An increase in the fibre volume fraction of up to $50 \%$ leads to an increase in tensile strength to $366 \mathrm{MPa}$, but once the fibre volume content exceeds $50 \%$ and continues through to a fibre volume content of $61 \%$ the tensile strength value remains almost constant at $373 \mathrm{MPa}$.

These tensile properties of samples with high fibre loading can be explained by non-sufficient fibre wetting, which increases at higher volume fractions. Comparing the fracture behaviour of a 33\%-

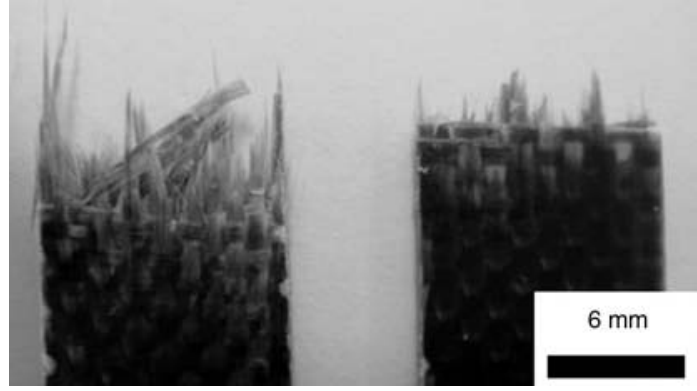

Figure 4. Fracture behaviour of composite specimens; left: $V_{f}=50 \%$, right: $V_{f}=33 \%$

sample and a 50\%-sample, it is evident that the former shows an almost linear fracture surface, while the latter exhibits a rather brush-like appearance, which suggests an increased fibre pull-out (Figure 4).

The behaviour of the elastic modulus in tension against the change of the fibre volume content is similar to the behaviour of the tensile strength. The elastic modulus value of $11.8 \mathrm{GPa}$, which was achieved with a fibre volume fraction of $32 \%$, initially went up as expected with the increase in the fibre volume fraction to $17.3 \mathrm{GPa}$ at $50 \%$. The modulus value, however, dropped to $15.8 \mathrm{GPa}$ with an increase in the fibre volume fraction to $61 \%$. The slightly increasing, and subsequently even decreasing values of the elastic modulus may be assigned to the higher void content and low interfacial shear strength, which resulted in less efficiency of load transfer with the increase in fibre content.

Figure 3 also presents the fracture strains of the composites as a function of the fibre volume content. It indicates that the strain values of the fibre reinforced samples are largely independent of the fibre content. This demonstrates that the fibres are the main load-bearing component in the tested fibre volume range.

Figure 5 shows the flexural strength and flexural modulus against the fibre volume fraction. The flexural strength and the flexural modulus show a steady linear rise with the increase in fibre content. The flexural strength rises from $73 \mathrm{MPa}$ at $V_{f}=24 \%$ to $122 \mathrm{MPa}$ at $V_{f}=51 \%$, and the flexural modulus increases within the same range of fibre content from 9.7 to $19.7 \mathrm{GPa}$.

During the three point-bending test, the lower layers are under tension and the upper layers are subject to compression. Flexural samples exhibit compressive fracture caused by fibre buckling failure. Buckling of fibres is mainly restricted by the sur- 

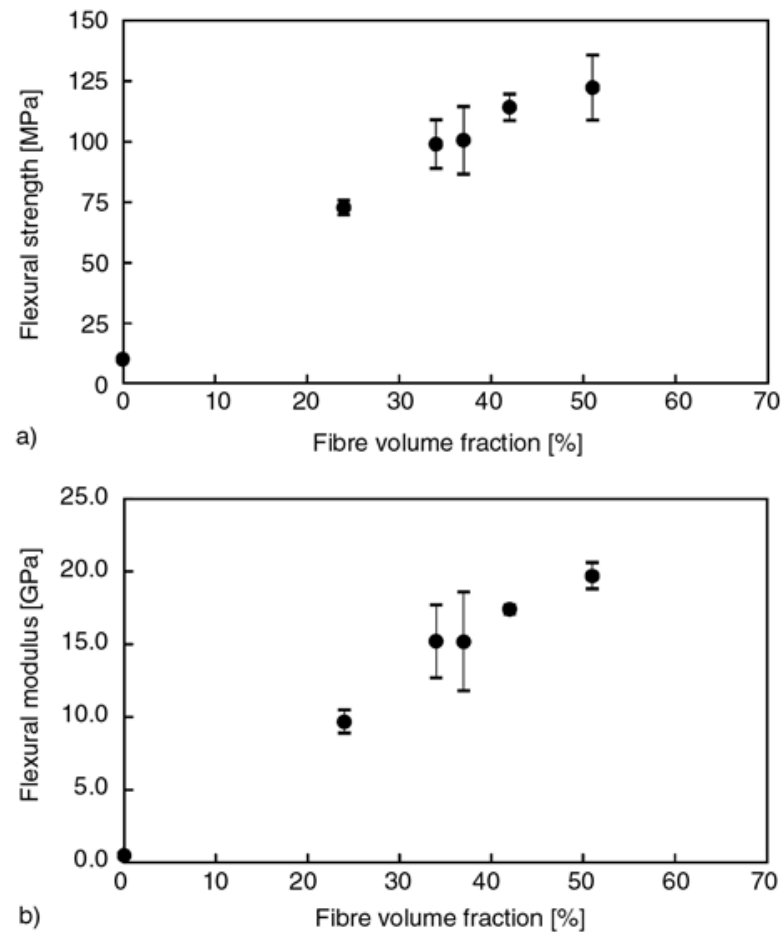

Figure 5. Effect of fibre volume fraction on flexural strength (a) and flexural modulus (b)

rounding matrix and, therefore, dependent on resin properties and the quality of fibre-matrix bond.

\subsection{Effect of silane coupling agent}

The results of the flexural tests on composites manufactured using desized and silane treated basalt woven cloth are summarised in Table 6.

Although no positive effect resulting from the APTS treatment was observed for flexural modu-

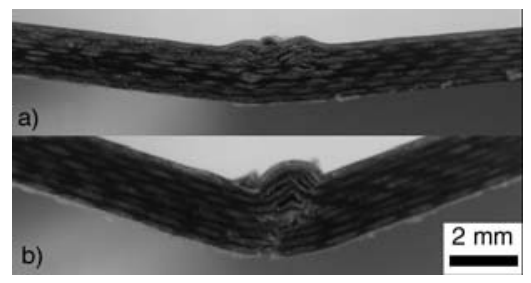

Figure 6. Flexural fracture behaviour of samples with untreated basalt fibres (a) and with fibres treated with APTS (1\%) (b) lus, treatment of the basalt fibres with $1 \mathrm{wt} \%$ aqueous APTS solution increased the composites' flexural strength by $38 \%$, from 99 to $136.6 \mathrm{MPa}$. Figure 6 shows the difference in the flexural fracture behaviour of $1 \mathrm{wt} \%$ APTS-treated samples and untreated samples. Both cases display fibre buckling in the upper compression layers. The fibre buckling of the APTS-treated sample, however, is limited to a smaller range of the sample length, indicating that higher compressive powers are needed to cause the buckling of the fibres. While in the untreated case fibre buckling is the main cause for compressive failure, the failure mode of the treated sample is a combination of compressive failure and tension failure by fibre failure in the lower layers, indicating a stronger fibre-matrix bond. With the increase in the concentration of the aqueous solution to $2 \mathrm{wt} \%$, the flexural strength remained virtually unchanged. A further increase up to $3 \mathrm{wt} \%$ led to a decrease in the flexural strength to $116.2 \mathrm{MPa}$.

As further shown in Table 6, composite samples with basalt fibres treated in 1\%-TSPI solution exhibited lower tensile strength values than samples with APTS-treated fibres, but still had a 17\% higher value than samples using as-received fibres. Although several mechanisms have been proposed to explain the interfacial reinforcement by silane coupling agents, chemical bonding is the most widely accepted [30]. Both coupling agents used in this study are ethoxy derivatives. Their chemical structure may be summarised as $\mathrm{RSi}(\mathrm{OEt})_{3}$, where OEt is the hydrolysable ethoxy group, and $\mathrm{R}$ the functional organic group. The ethoxy groups hydrolyse in the presence of water to form the silanol groups, the active agent in the reaction with the mineral surfaces.

The hydroxyl groups of the silanols then react with the hydroxyl groups of the basalt fibre surface through siloxane or hydrogen bonding (Figure 7). In addition to those reactions of silanols with

Table 6. Effect of silane coupling agent application on flexural properties; CP: CP-300 resin; BaF: basalt fibres; SA: APTS; SB: TSPI

\begin{tabular}{|c|c|c|c|c|}
\hline \multirow{2}{*}{ Sample designation } & \multicolumn{2}{|c|}{ Silane treatment } & \multirow{2}{*}{$\begin{array}{c}\text { Flexural strength } \\
\text { [MPa] }\end{array}$} & \multirow{2}{*}{$\begin{array}{c}\text { Flexural modulus } \\
{[\mathrm{GPa}]}\end{array}$} \\
\hline & Type & Solution content & & \\
\hline $\mathrm{CP} / \mathrm{BaF} 34 / \mathrm{SA}$ & APTS & $1 \%$ & $136.3 \pm 11.3$ & $15.2 \pm 1.0$ \\
\hline $\mathrm{CP} / \mathrm{BaF} 34 / \mathrm{SA} 2$ & APTS & $2 \%$ & $135.6 \pm 5.7$ & $13.1 \pm 1.0$ \\
\hline $\mathrm{CP} / \mathrm{BaF} 34 / \mathrm{SA} 3$ & APTS & $3 \%$ & $129.1 \pm 11.3$ & $14.5 \pm 0.9$ \\
\hline $\mathrm{CP} / \mathrm{BaF} 34 / \mathrm{SB}$ & TSPI & $1 \%$ & $116.2 \pm 9.3$ & $12.8 \pm 1.1$ \\
\hline
\end{tabular}




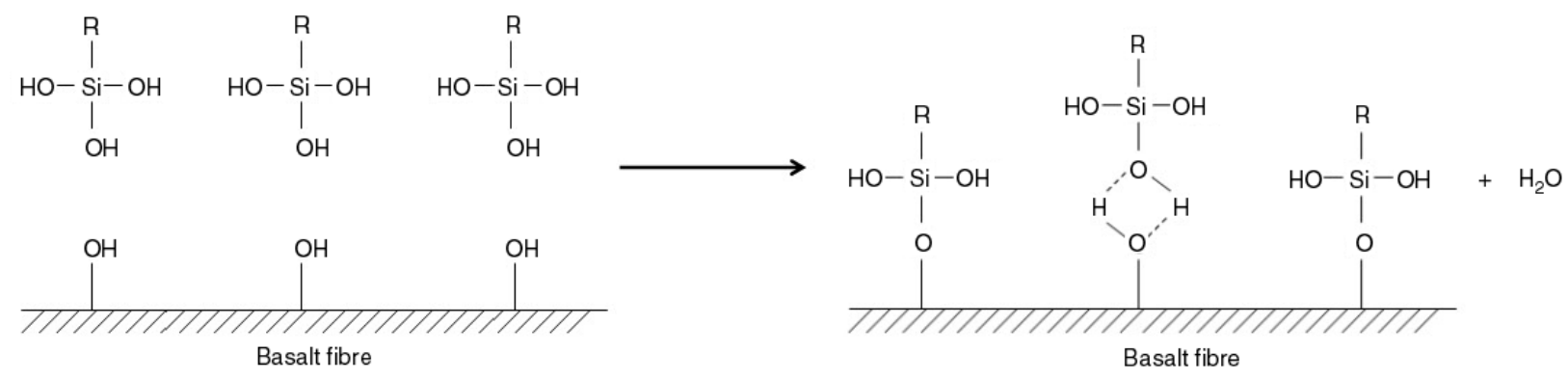

Figure 7. The bonding process of the silanol groups to the basalt fibre surface

hydroxyls on the fibre surface, the formation of polysiloxane structures also can take place [34].

In case of thermoplastic resins it is widely accepted that an interphase layer is generated. This layer may have partial solution compatibility with the matrix resin and forms an interpenetrating network (IPN) as the siloxanols and matrix resin cure separately with a limited amount of cross-linking [35]. The results of our study show that APTS has a higher compatibility with the thermoplastic constituents, PLC and starch, than TSPI and the proprietary sizing applied by the manufacturer.

An explanation for the decrease of the flexural strength with a concentration of $3 \mathrm{wt} \%$ may be connected with the thickness of the silane interphase. In general, more than one layer is necessary to form chemical bonds, an interpenetrating network and the proper orientation of functional groups. As the thickness of the deposited silanes increases, the non-bonded oligomeric interphase between the two main substrates of the composites has the opposite effect on the interfacial properties. This interphase has low mechanical strength and low resistance to environmental attack as the oligomeric interphases can be hydrolysed easily. An indicator of the existence of non-hydrolysed interphases might be the appearance of the woven cloth just after impregnation with the resin emulsion, as shown in Figure 8.

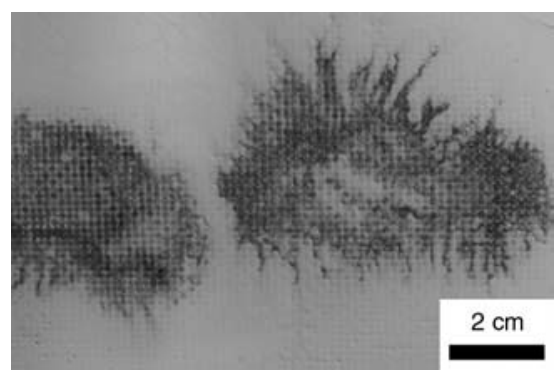

Figure 8. Appearance of freshly impregnated fibres, treated with $3 \mathrm{wt} \%$ APTS solution

As such flaws were only observed with plain weave treated with a concentration of $3 \mathrm{wt} \%$ APTS, it is conceivable that the reaction of non-hydrolysed ethoxy groups with the water from the emulsion was the cause of this phenomenon.

\subsection{Fire retardancy}

Table 7 shows combustion and flexural properties of non-reinforced CP resin and basalt fibre reinforced 'green' composites with and without application of fire retardant additives. The UL 94 horizontal test results for the non-reinforced $\mathrm{CP}$ resin display a very high burning rate, showing that the resin is highly flammable. Incorporation of approximately 34 vol\% of non-flammable natural basalt fibres into the resin results in a substantial decrease in the burning speed from 199 to $38 \mathrm{~mm} / \mathrm{min}$, lead-

Table 7. Composition of samples tested for combustion performance and effect of fire retardants on combustion performance and flexural properties; $x$ : specimens stopped burning; CP: CP-300 resin; BaF: basalt fibres, SA: APTS; RA: APTS and RP; RB: APTS and MH; RAB: APTS, RP and MH

\begin{tabular}{|c|c|c|c|c|c|c|c|c|c|c|}
\hline \multirow{2}{*}{$\begin{array}{c}\text { Sample } \\
\text { designation }\end{array}$} & \multicolumn{4}{|c|}{ Ingredients [wt\%] } & \multicolumn{4}{|c|}{ Burning rate $[\mathrm{mm} / \mathrm{min}]$} & \multirow{2}{*}{$\begin{array}{c}\text { Flexural } \\
\text { strength } \\
\text { [MPa] }\end{array}$} & \multirow{2}{*}{$\begin{array}{c}\text { Flexural } \\
\text { modulus } \\
{[\mathrm{GPa}]}\end{array}$} \\
\hline & $\begin{array}{c}\mathbf{C P} \\
\text { resin }\end{array}$ & $\begin{array}{l}\text { Basalt } \\
\text { fibres }\end{array}$ & $\mathbf{R P}$ & МH & UL 94 H & UL 94 V & UL 94 V7 & Rating & & \\
\hline $\mathrm{CP}$ & 100 & - & - & - & $199 \pm 95$ & - & - & NR & $10.2 \pm 0.3$ & $0.5 \pm 0.1$ \\
\hline $\mathrm{CP} / \mathrm{BaF} 34 / \mathrm{SA}$ & 45 & 55 & - & - & $38 \pm 4$ & - & - & HB & $136.3 \pm 11.3$ & $15.2 \pm 1.0$ \\
\hline CP/BaF34/RA9 & 36 & 55 & 9 & - & $x$ & $146 \pm 17$ & $155 \pm 18$ & $\mathrm{HB}$ & $99.6 \pm 6.1$ & $13.8 \pm 0.7$ \\
\hline $\mathrm{CP} / \mathrm{BaF} 34 / \mathrm{RA}$ & 40.5 & 55 & 4.5 & - & $x$ & $162 \pm 30$ & $176 \pm 17$ & HB & $107.4 \pm 4.8$ & $11.6 \pm 1.1$ \\
\hline $\mathrm{CP} / \mathrm{BaF} 34 / \mathrm{RB}$ & 40.5 & 55 & - & 4.5 & $x$ & $127 \pm 6$ & $133 \pm 4$ & HB & $103.8 \pm 3.7$ & $11.3 \pm 0.4$ \\
\hline $\mathrm{CP} / \mathrm{BaF} 34 / \mathrm{RAB}$ & 40.5 & 55 & 2.25 & 2.25 & $x$ & $146 \pm 5$ & $154 \pm 12$ & $\mathrm{HB}$ & $108.9 \pm 6.1$ & $13.1 \pm 1.0$ \\
\hline
\end{tabular}


ing to a $\mathrm{HB}$ rating for the composite even without the use of fire retardant additives. Applications of $\mathrm{RP}$ and $\mathrm{MH}$, respectively, result in further enhancement of burning behaviour by extinguishing the flaming of the horizontal samples after only a few seconds. This indicates that both additives can be effectively used as fire retardants for starch based basalt fibre reinforced composites at relatively low loadings.

In order to further investigate and to compare the effect of the fire retardant additives, vertical burning tests were conducted as well. The effect of the fire retardants on the burning rates of the vertical combustion samples can be seen in Figure 9. Composite samples with $4.5 \mathrm{wt} \% \mathrm{RP}$ displayed burning rates of 162 and $176 \mathrm{~mm} / \mathrm{min}$, respectively. While an increase in the RP loading to $9 \mathrm{wt} \%$ shows a $10 \%$ improvement in the flame retardancy, the replacement of $4.5 \mathrm{wt} \% \mathrm{RP}$ with the same amount of $\mathrm{MH}$ improves the composites flame retardancy by more than $20 \%$. The combination of RP with MH in a ratio of $1: 1$, with an overall fire retardant content of $4.5 \mathrm{wt} \%$, displayed about the same values as samples with $9 \mathrm{wt} \% \mathrm{RP}$, but showed lower values than samples with MH only.

Metallic hydroxides such as $\mathrm{MH}$ provide flame retarding effects by various mechanisms. Those mechanisms include [36]:
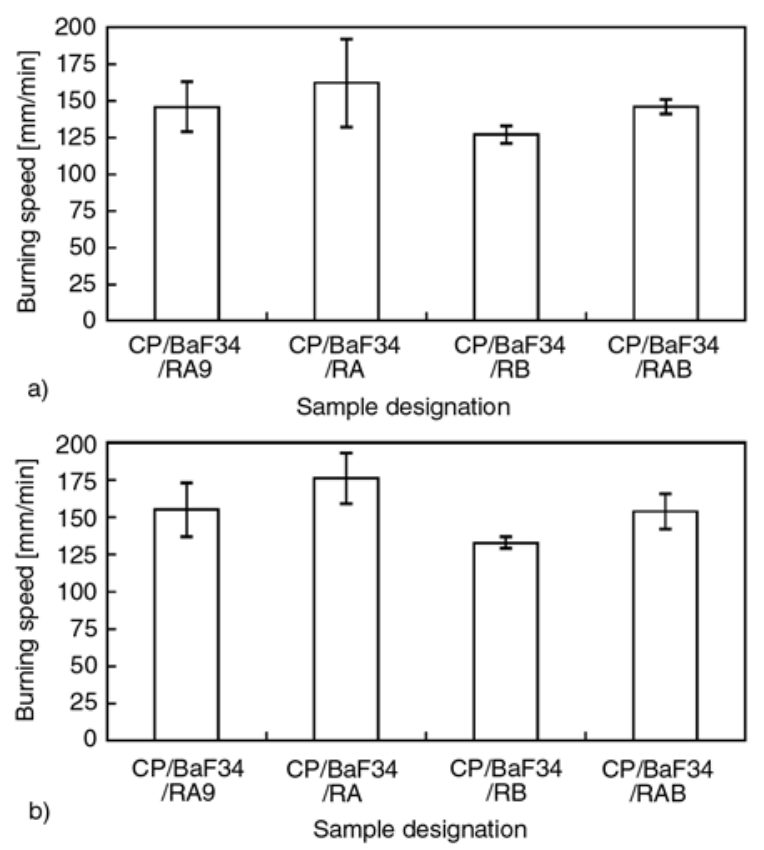

Figure 9. Effect of the fire retardant additives on UL 94 horizontal burning rate of samples stored for 2 days at RT (a) and 7 days at $60^{\circ} \mathrm{C}$ (b) before testing
- reduction of the temperature increase of the burning polymer and delay of ignition and flame propagation due to water releasing decomposition,

- reduction of combustible gas concentrations due to water moisture vapour,

- blocking of available oxygen caused by the generation of combustion barriers and delay of flame propagation by adiabatic effect,

- reduction of the amount of burnable material, and

- smoke reduction due to acceleration of the oxidative reaction of fine particle carbon (soot) caused by emerging $\mathrm{MgO}$.

$\mathrm{RP}$ is an amorphous polymeric modification of phosphorus. The fire retardancy effectiveness of RP depends slightly on the polymer used, because of different mechanisms which depend on the surrounding environment of RP particles. The retardancy of RP is based on its ability to turn into polyphosphoric acid derivatives while burning, facilitating the formation of char layers. This effect is efficient in the case of oxygen-bearing resins, but the efficiency decreases if the generation of char layers depends solely on oxygen found on the burning surface of the polymer [37].

Both fire retardants effectively reduce the flammability of the composite at low content. Although the oxygen content inherent in both starch and PCL was sufficient for RP to bring its fire retarding mechanism into effect, forming char layers as seen in Figure 10, MH displays higher retarding effectiveness with the same weight content. As further seen by the appearance of both specimens in Figure 10, the dominant fire retarding mechanism by application of $\mathrm{MH}$ was similar to the fire retardant mechanism of RP. For this reason, no synergistic

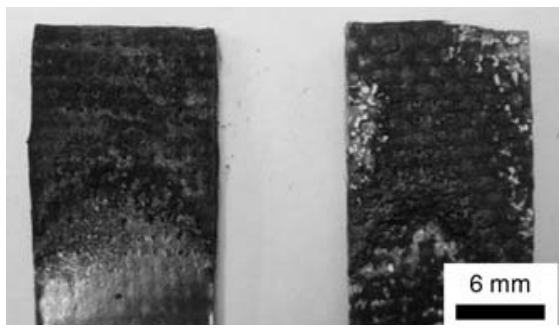

Figure 10. Photographs of specimens after UL 94 horizontal burning test of formulations with $4.5 \mathrm{wt} \%$ red phosphor (CP/BaF34/RA, left) and $4.5 \mathrm{wt} \%$ magnesium hydroxide (CP/BaF34/RB, right) 
effect was observed by using the fire retardants simultaneously.

Figure 11 shows the TGA curves of the flame retarded resins used in the sample designations $\mathrm{CP} /$ $\mathrm{BaF} 34 / \mathrm{RA}$ and $\mathrm{CP} / \mathrm{BaF} 34 / \mathrm{RB}$ containing $10 \mathrm{wt} \%$
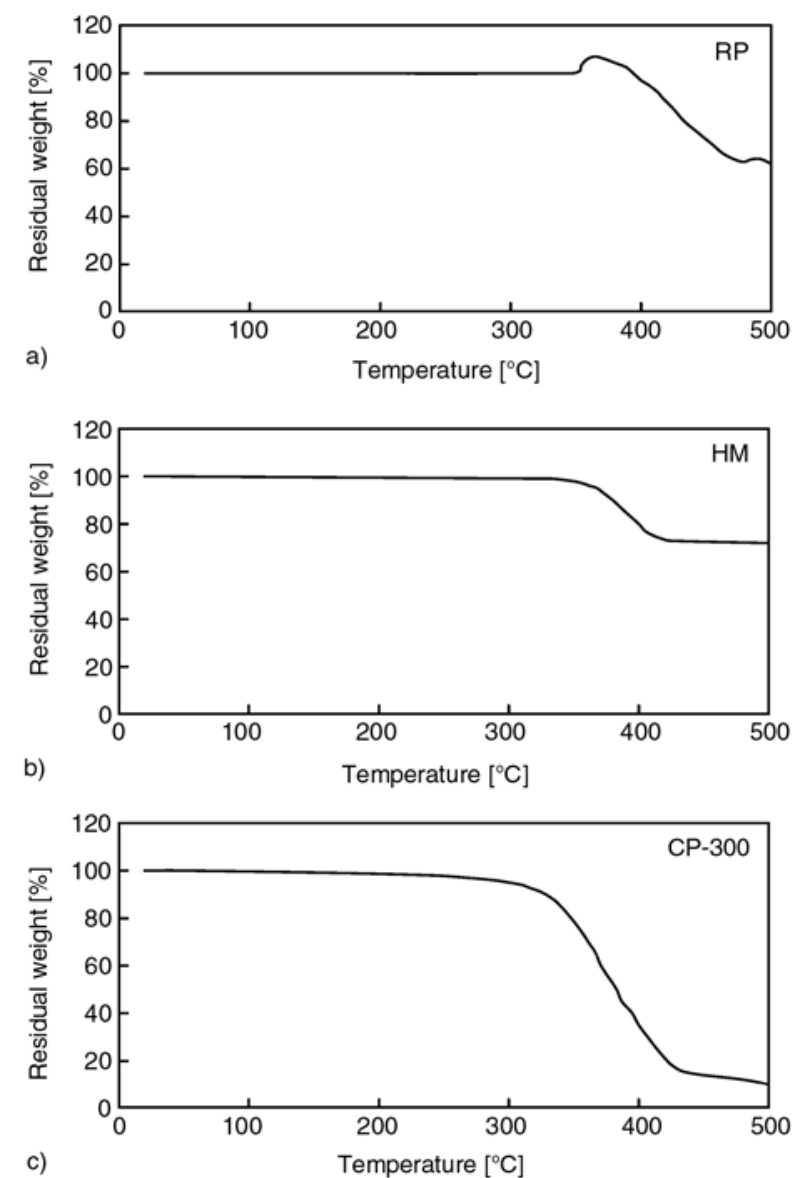

c)
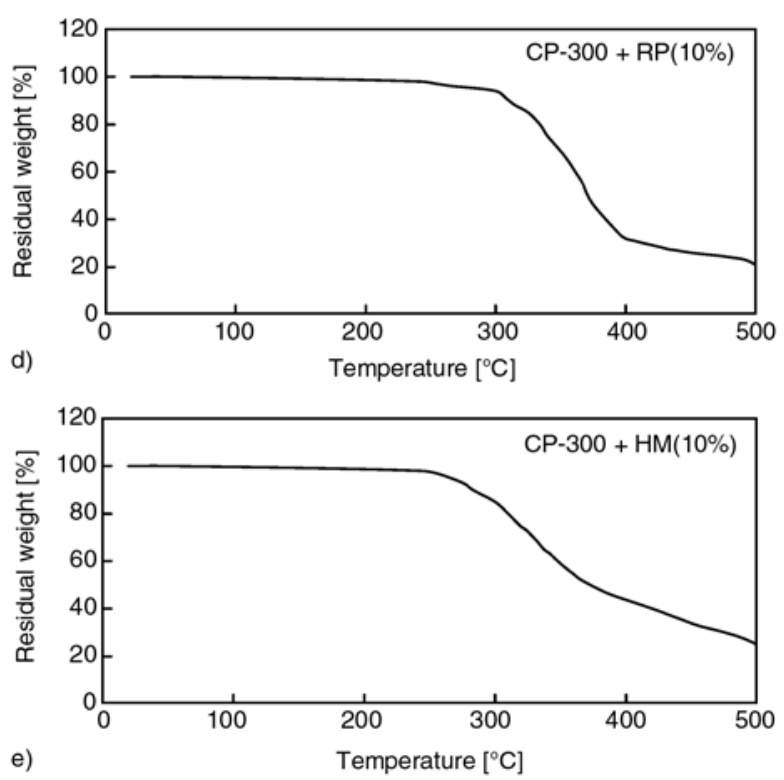

Figure 11. TGA curves of red phosphor (RP) (a), magnesium hydroxide (MH) (b), CP-300 base resin

(c) and mixtures of the base resin with $10 \% \mathrm{RP}$

(d) and MH (e), respectively
$\mathrm{RP}$ and $\mathrm{MH}$, respectively, together with the TGA curves of each flame retardant and the base resin CP-300. The decomposition of CP-300 starts at $250^{\circ} \mathrm{C}$, continues quickly and reaches a residual weight of $16 \%$ at $430^{\circ} \mathrm{C}$, with a remaining residue of $10 \%$ at $500^{\circ} \mathrm{C}$. Both flame retardants start to decompose at $350^{\circ} \mathrm{C}$. $\mathrm{MH}$ decomposes steadily until $410^{\circ} \mathrm{C}$ reaching a residual weight of $75 \%$ with a remaining residue of $72 \%$ at $500^{\circ} \mathrm{C}$. RP displays a slight mass increase at $350^{\circ} \mathrm{C}$ due to its highly oxidative character and then starts to decompose leaving a char residue of $62 \%$ at $500^{\circ} \mathrm{C}$. The effect of the flame retardants on the base resin can be clearly seen by looking at the residues at $500^{\circ} \mathrm{C}$. The amount of residue of CP-300 with 10\% RP is, with $21 \%$, twice as high as the amount in the case of the base resin. The value of CP-300 with $10 \%$ $\mathrm{MH}$ is, with $25 \%$, even higher. This indicates that the resulting char-like residue observed during the UL 94 tests and shown in Figure 10 is formed from the present flame retardants starting with the decomposition process of the base resin at around 250 to $300^{\circ} \mathrm{C}$.

Table 7 also displays the flexural properties of the flame retardant composite mixtures. Despite the application of the silane coupling agent, the addition of flame retardant additives shows a negative influence on the flexural properties of the composites, and the properties of the composites with $4.5 \%$ flame retardants display a reduction in flexural strength of 20 to $24 \%$. At the same loading values samples with RP only exhibited slightly better properties than samples with HM or with both retardants, which might be indicative of non-uniform distribution of HM inside the resin.

\section{Conclusions}

High strength bi-directional 'green' composites with woven basalt cloth as reinforcement and starch based resin as base material have been successfully manufactured through the utilization of a hot press machine and a doctor blade system. Furthermore, this study showed that by application of silane coupling agents compatible with the resin system, flexural properties of the composite could be improved significantly. The flammability behaviour of the base resin and of the composites with and without flame retardants, as well as the effect of flame retardant additives on the flexural proper- 
ties of basalt fibre reinforced starch based composite was studied. It was shown that basalt fibres are a natural reinforcement material which significantly improves the flammability behaviour of the thermoplastic matrix. It was further shown that magnesium hydroxide and red phosphor can effectively reduce the flammability of the composite with contents as low as $4.5 \mathrm{wt} \%$. The flexural properties of the retardant-filled composite exhibited a slight decrease compared to the composite without flame retardants, but at the same time showed better properties compared to the composites without treatment with silane coupling agent compatible to the polymer system.

Further tests, especially on durability and resistance against environmental conditions, have to be performed in order to evaluate the application possibilities of the developed material and to assess if basalt fibre reinforced CP-300 is adaptive for parts which are exposed to environmental influences, as for example automotive under body panels.

\section{Acknowledgements}

The authors gratefully acknowledge financial support by the Itoyama International Foundation and the Rotary Yoneyama Memorial Foundation. Furthermore, the authors would like to thank Miyoshi Yushi Inc. for supplying the base resin, and Rinkagaku Kogyo Ltd. and Albemarle Overseas Development Corporation, Japan, for supplying the fire retardant additives.

\section{References}

[1] Stamboulis A., Baille C., Peijs T.: Effects of environmental conditions on mechanical and physical properties of flax fibers. Composites Part A: Applied Science and Manufacturing, 32, 1105-1115 (2001).

[2] Bismarck A., Mishra S., Lampke T.: Plant fibres as reinforcement in green composites. in 'Natural Fibers, Biopolymers and Biocomposites' (eds.: Mohanty A. K., Misra M., Drzal L. T.) Taylor and Francis, Boca Raton, 37-108 (2005).

[3] Wootthikanokkhan J., Santikunakorn S.: Effects of propionyl content on the morphology, mechanical properties, and biodegradability of esterified cassava starch/polycaprolactone blends. Journal of Applied Polymer Science, 96, 2154-2162 (2004).

[4] Wu C-S.: Performance of an acrylic acid grafted polycaprolactone/starch composite: Characterization and mechanical properties. Journal of Applied Polymer Science, 89, 2888-2895 (2003).
[5] Kim E. G., Kim B. S., Kim D. S.: Physical properties and morphology of polycaprolactone/starch/pine-leaf composites. Journal of Applied Polymer Science, 103, 928-934 (2007).

[6] Dzhigiris D. Z., Makhova M. F., Gorobinskaya V. D., Bombyr L. N.: Continuous basalt fiber. Glass and Ceramics, 40, 467-470 (1983).

[7] Morozov N. N., Bakunov V. S., Morozov E. N., Aslanova L. G., Granovskii P. A., Prokshin V. V., Zemlyanitsyn A. A.: Materials based on basalts from the european north of russia. Glass and Ceramics, 58, 100-104 (2001).

[8] Sokolinskaya M. A., Zabava L. K., Tsybulya T. M., Medvedev A. A.: Strength properties of basalt fibers. Glass and Ceramics, 48, 435-437 (1991).

[9] Militky J., Kovacic V.: Ultimate mechanical properties of basalt filaments. Textile Research Journal, 66, 225-229 (1996).

[10] Gur'ev V. V., Neproshin E. I., Mostovoi G. E.: The effect of basalt fiber production technology on mechanical properties of fiber. Glass and Ceramics, 58, 62-65 (2001).

[11] Czigány T.: Basalt fiber reinforced hybrid polymer composites. Materials Science Forum, 473-474, 5966 (2005).

[12] Kogan F. M., Nikitina O. V.: Solubility of chrysotile asbestos and basalt fibers in relation to their fibrogenic and carcinogenic action. Environmental Health Perspectives, 102, 205-206 (1994).

[13] Czigány T., Vad J., Pölöskei K.: Basalt fiber as a reinforcement of polymer composites. Periodica Polytechnica, Mechanical Engineering, 49, 3-14 (2005).

[14] Szabó J. S., Czigány T.: Material properties: Static fracture and failure behavior of aligned discontinuous mineral fiber reinforced polypropylene composites. Polymer Testing, 22, 711-719 (2003).

[15] Vas L. M., Pölöskei K., Felhős D., Deák T., Czigány T.: Theoretical and experimental study of the effect of fiber heads on the mechanical properties of non-continuous basalt fiber reinforced composites. Express Polymer Letters, 1, 109-121 (2007).

[16] Matkó S., Anna P., Marosi G., Szép A., Keszei S., Czigány T., Pölöskei K.: Use of reactive surfactants in basalt fibre reinforced polypropylene composites. Macromolecular Symposia, 202, 255-267 (2003).

[17] Ozawa Y., Kikuchi T., Isohata M.: Mechanical behavior of basalt fiber reinforced polymer composites in temperature condition. in 'Proceedings of $3^{\text {rd }}$ International Workshop on Green Composites (IWGC-3). Kyoto, Japan' 124-127 (2005).

[18] Liu Q., Shaw M. T., Parnas R. S., McDonell A. M.: Investigation of basalt fiber composite mechanical properties for applications in transportation. Polymer Composites, 27, 41-48 (2006).

[19] Liu Q., Shaw M. T., Parnas R. S., McDonell A-M.: Investigation of basalt fiber composite aging behavior for applications in transportation. Polymer Composites, 27, 475-483 (2006). 
[20] Ye P., Reitz L., Horan C., Parnas R.: Manufacture and biodegradation of wheat gluten/basalt composite material. Journal of Polymers and the Environment, 14, 1-7 (2006)

[21] Wittek T., Tanimoto T.: Biodegradable starch-based resin reinforced with continuous mineral fibres - Processing, characterisation and mechanical properties. Advanced Composite Materials, in press (2008).

[22] Matkó S., Toldy A., Keszei S., Anna P., Bertalan G., Marosi G.: Flame retardancy of biodegradable polymers and biocomposites. Polymer Degradation and Stability, 88, 138-145 (2005).

[23] Tanaka H.: Starch emulsion (in Japanese). Engineering Materials, 51, 58-62 (2003).

[24] Park J. M., Subramanian R. V.: Interfacial shear strength and durability improvement by monomeric and polymeric silanes in basalt fiber/epoxy single-filament composite specimens. Journal of Adhesion Science and Technology, 5, 459-477 (1991).

[25] Park J. M., Subramanian R. V., Bayoumi A. E.: Interfacial shear strength and durability improvement by silanes in single-filament composite specimens of basalt fiber in brittle phenolic and isocyanate resin. Journal of Adhesion Science and Technology, 8, 133150 (1994)

[26] Park J-M., Shin W-G., Yoon D-J.: A study of interfacial aspects of epoxy-based composites reinforced with dual basalt and SiC fibres by means of the fragmentation and acoustic emission techniques. Composites Science and Technology, 59, 355-370 (1999).

[27] Park J-M., Chong E-M., Yoon D-J., Lee J-H.: Interfacial properties of two SiC fiber-reinforced polycarbonate composites using the fragmentation test and acoustic emission. Polymer Composites, 19, 747-758 (1998).
[28] Tanimoto T.: Continuous-fibre CMC fabrication by using pre-impregnated sheets. Composites Part A: Applied Science and Manufacturing, 30, 583-586 (1989).

[29] Kobayashi T., Takahashi S., Fujii N.: Silane coupling agent having dithiocarbamate group for photografting of sodium styrene sulfonate on glass surface. Journal of Applied Polymer Science, 49, 417-423 (1993).

[30] Plueddemann E. P.: Silane coupling agents. Plenum Press, New York (1982).

[31] JIS K 7113: Testing method for tensile properties of plastics (1995).

[32] JIS K 7017: Fibre-reinforced plastics composites Determination of flexural properties (1999).

[33] JIS K 6911: Testing methods for thermosetting plastics (1995).

[34] Arkles B., Steinmetz J. R., Zazyczny J., Mehta P.: Factors contributing to the stability of alkoxysilanes in aqueous solutions. Journal of Adhesion Science and Technology, 6, 193-206 (1992).

[35] Plueddemann E. P.: Reminiscing on silane coupling agents. Journal of Adhesion Science and Technology, 5, 261-277 (1991).

[36] Hornsby P. R., Watson C. L.: Mechanism of smoke suppression and fire retardancy in polymers containing magnesium-hydroxide filler. Plastics and Rubber Processing and Applications, 11, 45-51 (1989).

[37] Troitzsch J.: Plastics flamability handbook: Principles, regulations, testing and approval. Hanser Publishers, Munich (2004). 